\title{
REPRESENTAÇÕES DE UM GRUPO DE DOCENTES SOBRE DROGAS: ALGUNS ASPECTOS
}

\author{
Cláudia Virginia Galindo Cavalcante ${ }^{1}$ \\ Daisi Teresinha Chapani ${ }^{1}$ \\ Vagner da Silva Sena ${ }^{2}$ \\ Jamile Souza Damasceno ${ }^{2}$ \\ Elaine Silva Alexandre ${ }^{2}$ \\ Wagner Barbosa Matias².
}

\section{RESUMO:}

O abuso de drogas é atualmente um grave problema de saúde pública e a escola básica deve contribuir com a sua prevenção. O objetivo do trabalho foi identificar as representações sociais dos professores de um grupo de professores de educação básica sobre drogas. Utilizamos como instrumento de coleta de dados um formulário que continha a seguinte sentença: Para você, drogas são... , aplicado a um grupo de 75 docentes. Utilizando procedimentos da análise de conteúdo buscamos identificar alguns aspectos das representações destes profissionais. Verificamos que estes entendem drogas como algo extremamente maléfico, que produz danos muitas vezes irreversíveis. Programas de formação inicial e continuada devem levar em consideração estas representações e colaborar na ampliação destas.

Palavras chave: docentes, representações socais, drogas de abuso.

\section{ABSTRACT}

The abuse of psychtropic drugs is nowadays a serious problem of public health and the basic school is called to contribute with its prevention. We judge it's important to identify the social representations of a group of teachers of basic education about drugs. For this we used a form with the following sentence: For you, drugs are... . Taking this as base procedures to the analyse of content seeking to identify some aspects of the representations of this professional group. We verified that they understand drugs as something extremely harmful, that produce psycological, physical, social, spiritual and moral damages, most times irreversible. Concluded that the programs of beginning continued formation of teachers must colaborate in the magnification of these representations also to provoke a transformation in the teaching practice.

Key words: teachers, social representation, drugs of abuse, prevention

\footnotetext{
${ }^{1}$ Prof. Ms. Assistente do Departamento de Ciências Biológicas da UESB-Jequiè
} 


\section{1- INTRODUÇÃO}

São consideradas drogas quaisquer substâncias capazes de provocar modificações em um organismo. Drogas psicoativas são aquelas que agem sobre o sistema nervoso central causando alterações na maneira de pensar, sentir e de agir.

De acordo com o documento Política Nacional Antidrogas (BRASIL, 2001) "o uso indevido de drogas constitui, na atualidade, séria e persistente ameaça à humanidade e à estabilidade das estruturas e valores políticos, econômicos, sociais e culturais de todos os Estados e sociedades" (p.7). Além disso, este uso está relacionado ao tráfico das drogas ilícitas e aos crimes conexos, afeta a segurança dos trabalhadores e a produtividade das empresas e se constitui em fator de elevação do número de casos de doenças graves.

Nota-se o aumento do consumo de certas drogas entre estudantes de escolas básicas (GALDURÓZ; NOTO; CARLINI, 1997), o que vem a causar uma série de danos biopsicosociais envolvendo tanto os usuários quanto à comunidade escolar.

É esperado que a escola colabore na redução destes problemas, assumindo o seu papel de agente preventivo. $\mathrm{O}$ ambiente escolar é propício para esta finalidade, pois serve como espaço educativo capaz de desenvolver trabalho sistemático e contínuo, além de ser um local onde se encontram crianças e jovens de diferentes faixas etárias, particularmente daquela típica em que ocorre o início do consumo regular dessas substâncias.

Segundo Bucher (1993 p. 51) "os educadores sentem-se despreparados para (...) para abordar a questão, seja em sala de aula ou fora dela". Desta forma a capacitação destes profissionais deveria ser priorizada pelas políticas públicas em educação.

Programas de formação inicial e continuada de docentes devem levar em conta os conhecimentos prévios e representações que estes possuem sobre o assunto, no entanto, encontramos poucas pesquisas com relação a este tema, aliás, como adverte Soares e Jacobi (2000 p. 214) a respeito de prevenção é notória "a ausência de trabalhos empíricos que tomem como referência o espaço educacional."

Assim, o objetivo deste estudo foi analisar alguns aspectos das representações de um grupo de docentes da escola básica sobre drogas.

\footnotetext{
${ }^{2}$ Graduandos da UESB-Jequié
} 


\section{2 - REFERENCIAIS TEÓRICOS}

\section{1 - Representações sociais}

"As representações sociais equivalem a um conjunto de princípios construídos interativamente e compartilhados por diferentes grupos que através delas compreendem e transformam a realidade" ( REIGOTA, 1995, p. 70)

Diferentemente dos conceitos científicos que já estão bem definidos dentro de determinada disciplina, as representações sociais são "o senso comum que se tem sobre determinado tema, onde se incluem também os preconceitos, ideologias e as características específicas das atividades cotidianas (sociais e profissionais) das pessoas" (MOSCOVICI APUD REIGOTA, 1995, p.12 ).

Para Leopardi (2001 p 243),

As representações sociais correspondem a um conjunto de conceitos, afirmações e explicações originadas no cotidiano, no decurso de comunicações intersubjetivas, podendo ser comparadas a uma versão contemporânea do senso comum. É um sistema de elaboração cognitiva (parcela individual da elaboração do conhecimento), afetiva (elaboração simbólica e aceitação no imaginário) e social (constituição compartilhada das imagens registradas)

Anadón e Machado (2003) apontam para o caráter dialético deste constructo tendo em vista estudos que demonstram que mudanças nas representações provocam alterações na prática, assim como transformações que levam a alterações na prática social requerem novos esquemas ordenadores, modificando as representações sociais sobre determinado fenômeno. Assim, cremos que as representações sociais destes docentes sobre drogas devem influenciar suas atitudes com relação às mesmas, inclusive no que tange às ações de prevenção que estes participam no ambiente escolar.

Para Wagner (1995 p 149) "o conceito de representação social é multifacetado". Seus estudos tanto podem ser guiados para o entendimento do processo de construção de objetos sociais que envolve comunicação e discurso, quanto para a elucidação de "estruturas individuais de conhecimento, símbolos e afetos distribuído entre as pessoas em grupo ou em sociedade". É esta segunda abordagem que utilizaremos neste estudo. 


\section{2 - Drogas e prevenção}

A questão do consumo de drogas é bastante complexa e devem ser considerados, além da própria substância psicoativa, o contexto sócio econômico e a pessoa do usuário. Quando estes três fatores são confluentes (droga, indivíduo e contexto social) pode-se instalar a dependência. Assim, é adequado distinguir entre uso e abuso de drogas, bem como os diferentes tipos de usuários (BUCHER, 1992).

Atualmente considera-se que a prevenção às drogas no contexto escolar deve ser tratada no âmbito mais geral da educação em saúde (BRASIL, 1998, DELGADO; PABLOS; SANCHES, 2002). A qual deve ser analisada em toda sua complexidade, avaliando-se os múltiplos fatores que a determina. Assim sendo, deve-se levarem conta os fatores de risco e proteção ${ }^{3}$ que podem ser oferecidos pela escola, no que diz respeito, inclusive, ao uso de drogas.

Bucher (1992), acredita que a abordagem preventiva ás drogas deve visar à elaboração de uma verdadeira ecologia humana, com o objetivo de transmitir a idéia da valorização da vida de uma maneira mais ampla à população, promovendo intervenções conscientes baseadas na reflexão ética sobre os valores humanos que a elas dão sentido.

De acordo com os Parâmetros Curriculares Nacionais - PCNs (BRASIL, 1998, p. 273) "as drogas psicoativas podem assumir um papel importante na vida dos adolescentes como recursos facilitadores da comunicação, da busca do prazer ou na lida com os novos desafios que se apresentam." Daí, a grande expectativa criada em torno da capacidade da escola e dos professores promoverem a prevenção ao uso destas substâncias. Para os PCNs: "é inegável que a escola seja um espaço privilegiado para o tratamento do assunto, pois o discernimento no uso de drogas está diretamente relacionado à formação e às vivências afetivas e sociais de crianças e jovens, inclusive no âmbito escolar" (BRASIL, 1998, p.271).

Assim, os PCNs enfatizam que este tema deve possuir uma abordagem transversal, ou seja, permeando toda a prática educativa. Estes documentos consideram ainda, em determinadas realidades, que o consumo de drogas é fator de risco já entre alunos das primeiras séries do ensino fundamental, daí sua inclusão nos PCNs de $1^{\circ}$ e $2^{\circ}$ Ciclos do Ensino Fundamental (BRASIL, 1997). Por estas razões acreditamos importante averiguar as representações de docentes que trabalham inclusive com esta faixa escolar.

\footnotetext{
3 "Fatores de riscos são aquelas circunstâncias sociais ou características da pessoa que a tornam mais vulneráveis a assumir comportamentos arriscados, como usar drogas. Fatores de proteção são aqueles que contrabalançam as vulnerabilidades, tornando a pessoa com menos chance de assumir esses comportamentos” (MARQUES, s.d)
} 


\section{3 - MATERIAIS E MÉTODO}

Foram sujeitos da pesquisa 75 professores, de ambos os sexos (embora predominantemente do feminino), que lecionam em classes de educação infantil, das primeiras séries do ensino fundamental e em turmas de educação de jovens e adultos. Estes participam de um programa de formação em serviço que visa graduar em Pedagogia professores que atuam em escolas municipais de Ipiau (BA) e região.

A coleta de dados ocorreu no mês de julho de 2004, em momento imediatamente antecedente a uma palestra sobre o assunto. Estavam presentes aproximadamente 120 docentes que foram informados da razão da pesquisa, destes, apenas 75 atenderam a solicitação preenchendo o formulário distribuído. Este constou de uma única expressão, a qual deveria ser completada pelo docente, a saber: Para você, drogas são....

O formulário não pedia qualquer forma de identificação e foi preenchido pelo próprio professor e entregue em seguida. Depois de repetidas leituras das respostas apresentadas, foram estabelecidas algumas categorias para análise conforme foram sendo identificadas semelhanças entre as idéias presentes em cada resposta, este procedimento, baseia-se na técnica de análise de conteúdo (GOMES, 1994).

\section{4 - RESULTADOS}

Muito embora a palavra droga possa ter, em seu uso cotidiano, muitos significados ${ }^{4}$, tomando-se o contexto da coleta de dados, consideramos que as respostas apresentadas pelos participantes da pesquisa estão relacionadas às drogas de abuso.

Efetuada análise das respostas dadas pelos docentes percebe-se que apresentam uma percepção bastante negativa e muitas vezes alarmista sobre drogas. Notou-se que estes procuram explicar as drogas a partir de alterações, danos e prejuízos que estas causam ao indivíduo, à família e à sociedade. Parte dos sujeitos considera estas situações irreversíveis, enquanto em outras respostas a noção de irreversibilidade não ficou clara, os demais definem drogas a partir da justificativa para seu uso. Portanto, enquadramos as respostas apresentadas em três categorias não excludentes, conforme apresentadas na Tabela 1

\footnotetext{
${ }^{4}$ De acordo com o Dicionário Aurélio: Sf. 1 - qualquer substância ou ingrediente que se usa em farmácia, em tinturaria etc. 2 - Med. Qualquer sustância que possa ser empregada no homem ou em outros animais, com o fim de diagnóstico, de tratamento ou de profilaxia de doença. 3 - produto oficinal, de origem animal ou vegetal, no estado em que se encontra no comércio. 4 - Substância entorpecente, alucinógena, excitante etc, com p. ex., a maconha, o haxixe, a cocaína, ministrada por via oral, ou por outras, ger. com o fito que o usuário passe,
} 
Tabela 1 - Freqüência relativa das características dadas às drogas pelos pesquisados, em relação ao número de asserções $(n=81)$.

\begin{tabular}{l|l|l|l}
\hline Categoria & Descrição das categorias & Abs. & $\%$ \\
\hline A & Danos, alterações e prejuízos irreversíveis & 34 & 41,97 \\
\hline B & Danos, alterações e prejuízos não irreversíveis & 33 & 40,74 \\
\hline C & Justificativas para uso & 13 & 16,05 \\
\hline D & Tautológicas & 1 & 1,23 \\
\hline
\end{tabular}

Foram enquadradas na categoria $A$, respostas que traziam a idéia de que as drogas produzem problemas irreversíveis, exemplos: "substâncias que destroem os seres vivos"; "uma catástrofe onde quem consome sempre fica a mercê da violência, enfim, das conseqüências que virão pela frente"; "o caminho pra a destruição do ser humano".

Foram enquadradas na categoria $B$, respostas cuja idéia central era que as drogas causam alterações nos usuários e malefícios sem, no entanto, especificar que estes sejam irreversíveis, exemplos: "coisas que fazem muito mal aos seres humanos, causando-lhes sérias conseqüências"; "tudo aquilo que é prejudicial à nossa saúde"; "tudo que não presta, que atrapalha sua vida e a vida dos outros"

Foram enquadradas na categoria $C$ aquelas respostas em que os docentes usaram expressões que indicam que as drogas sejam utilizadas como meio de superação de determinadas situações como: "desequilíbrio, refúgio"; "utilização indevida de remédios ou ervas que levam o indivíduo a fugir de sua realidade"; "baixa auto-estima" .

Encontrou-se ainda uma resposta tautológica, na qual o docente completou a frase afirmando que "drogas são.... drogas", demonstrando, pelo uso do artifício do slogan uma falta de definição própria elaborada pelo sujeito.

Visto que muitos docentes buscaram definir drogas a partir de danos, alterações e prejuízos irreversíveis ou não causados pelas mesmas, classificamos as respostas dadas de acordo com os tipos de alterações aludidas. Das 75 respostas obtidas, 22 delas explicitavam tais tipos que foram classificados nas seguintes categorias: físicas, psicológicas, sociais, espirituais e morais, sendo que as mesmas não são excludentes, conforme demonstrado na Tabela 2. 
Tabela 2 - Freqüência relativa dos tipos de alterações causadas pelas drogas, segundo os pesquisados, em relação ao número de asserções $(n=32)$.

\begin{tabular}{l|l|l|l}
\hline Categoria & & Abs. & $\%$ \\
$\mathrm{E}$ & Psicológicos & 13 & 40,62 \\
$\mathrm{~F}$ & Físicas & 8 & 25,00 \\
$\mathrm{G}$ & Sociais & 8 & 25,00 \\
$\mathrm{H}$ & Espirituais & 2 & 6,25 \\
$\mathrm{I}$ & Morais & 1 & 3,12
\end{tabular}

Com relação à categoria $E$ temos os seguintes exemplos: "uma porcaria que envenena a mente das pessoas"; "substâncias que enlouquecem a mente das pessoas"; "um mal sinal que afeta e destrói a mente a e vida dos jovens"

Como exemplos de respostas enquadradas na categoria $F$ : "todas as substâncias químicas que provocam e traz um desequilíbrio orgânico"; tudo que prejudica o organismo, trazendo graves conseqüências para o futuro"; "todas as substâncias que entorpecem o organismo, causando mudanças na maneira de agir, pensar etc ".

$\mathrm{Na}$ categoria G foram enquadradas respostas como: "são elementos prejudiciais à saúde mental e social do homem" ; "maléfica, pois destroem não apenas o usuários e a família"; "tudo que não presa, que atrapalha a sua vida e a vida dos outros".

Como exemplos das respostas enquadradas na categoria $\mathrm{H}$, temos: "as destruições das próprias vidas, da família e da sociedade, consumindo sustâncias que são prejudiciais no seu aspecto espiritual e material para o desenvolvimento do ser humano"; "destruição, desconforto, desamor, caos, pobreza, polêmica, desestruturação, desfiguração, perda do amor a Deus, a si e à família".

A resposta enquadrada na categoria I foi: "substâncias químicas que quando utilizadas causam dependência tornando os usuários escravos das mesmas levando-os a perder seus valores, sua dignidade, personalidade e até mesmo o caráter."

\section{5 - DISCUSSÃO}

Spink (1995) adverte para a heterogeneidade e, até mesmo, contradições existentes nas representações sociais o que não impede a possibilidade de consensos. Desta forma, percebemos no grupo pesquisado, diferentes entendimentos sobre drogas, mas predominantemente a percepção de que estas são extremamente maléficas. De forma geral, 
as referências a estas substâncias foram sempre negativa, por exemplo, das 75 respostas obtidas, 22 delas $(29,33 \%)$ continham a palavra destruição.

Notamos que estes docentes consideram que os malefícios causados pelas drogas decorrem de sua natureza e não da sua forma de consumo, a não ser em um único caso em que o pesquisado respondeu que "pode ser algo prejudicial no seu mau uso", e em outra resposta que cita o uso de drogas como medicamentos "tristeza, insatisfação pessoal, vingança, uma forma de desabafar seus sentimentos, saúde ou doença (usada na cura de doenças e também pode adquirir muitas doenças)".

Percebemos nas respostas apresentadas que o contexto do uso, bem como as diferenças individuais dos usuários não foram aludidas. Neste caso, é necessário, evidentemente, levar em consideração as limitações do instrumento de coleta de dados que se referia explicitamente às drogas e não aos demais aspectos.

Pelas expressões enfáticas e muitas vezes alarmistas utilizadas pelos sujeitos, deduzimos que ao aludirem às drogas, estes se referem a situações extremas, mais relacionadas à dependência que às outras formas de consumo das mesmas. Para Lima (1996) há um pensamento generalizado que os usuários de drogas compõem um conjunto de pessoas e hábitos homogêneos, tomando-se como base um padrão criado pelos nãousuários. Assim, a categoria drogado só é homogênea e descontínua se considerada a partir de um olhar superficial e ligeiro.

Soares e Jacobi (2000) perceberam que entre professores e supervisores que participaram de um projeto de prevenção, alguns ainda permaneceram com idéias preconcebidas como por exemplo com relação ao perfil do usuário "visão que uniformiza todos os usuários de drogas, em geral como fracos, estranhos, com problemas familiares etc".

È possível que a construção desta imagem do chamado "mundo das drogas" deva-se tanto às experiências pessoais quanto à influência de uma cultura geral, cuja ideologia está implícita nos discursos de "combate às drogas" presente na sociedade, especialmente na grande mídia (BUCHER; OLIVEIRA, 1994; LIMA, 1996, RIBEIRO; PERGHER;TOROSSIAN, 1998) e inclusive nos livros didáticos (CARLINI-COTRIM; ROSEMBERG, 1991).

No que diz respeito à condução de ações de prevenção no contexto escolar, este entendimento pode impedir o florescimento de alternativas mais eficientes, de acordo com o abordado na literatura científica (BUCHER, 1992, 1993 DOMANICO; BRITES, 1996 ARATANGY 1996) a qual enfatiza que as diferentes formas de uso de drogas devem ser consideradas. Para Aratangy (1996 p.115) um programa eficiente de prevenção deve "respeitar a inteligência dos jovens, não usando mensagens alarmistas e deformadas (não tratar, por exemplo, todas as drogas como se oferecessem o mesmo risco, não confundir o uso eventual de uma substância psicoativa com o uso habitual e contínuo)" . 
Como alertam os PCNs " em contradição às práticas visíveis aos jovens e que permeiam o cotidiano de sua vivência social, os discursos de combate às drogas sugerem que elas são produtos ilegais e misteriosos e seus consumidores são os outros, marginais e traficantes, as serem excluídos do convívio social” (BRASIL, 1998 p. 272)

Uma parcela dos docentes pesquisados tenta explicitar sua percepção de drogas a partir de justificativas para o uso destas substâncias. Segundo Bucher (1993) as razões geralmente invocadas para o uso e abuso de drogas são: necessidade de fugir de problemas, busca de prazer, desvio do desprazer e outras contraditórias, como: acalmar ou estimular, ficar acordado ou dormir, afastar-se dos problemas ou melhor enfrentá-los e ainda por atitudes de contestação, transgressão ou desobediência.

As drogas, através do esquecimento que provocam a respeito de sentimentos como: solidão, sensação de vazio, angustias, sofrimentos e depressão, permitem uma fuga do indivíduo de si mesmo, alimentando a esperança de banir em definitivo "o espectro da divisão sofrida". Entretanto, ao se recorrer às drogas a pessoa não elimina os riscos inerentes à vida, mas os incrementa (BUCHER, 1992 p. 29).

Assim, vemos que algumas das justificativas apontadas pelos docentes para uso de drogas não se afastam muito daquelas invocadas pelos usuários, no entanto, notamos aqui novamente, que possivelmente estes professores estejam referindo-se às drogas ilícitas ou ao uso abusivo, pois se deve considerar que em nossa sociedade, é bastante comum (provavelmente inclusive entre os pesquisados) o uso de drogas lícitas em situações sociais, muitas vezes relacionadas a momentos de celebração, nas quais seu uso nem sempre se justifica por falta de "auto-estima", "fuga da realidade", "incapacidade de amar a si próprio", "fraqueza" etc.

Desta forma, percebemos, assim como Bucher (1993), que é necessário que a formação docente colabore na desmistificação desta questão, para que os educadores a considerem numa perspectiva mais realista.

Além disso, tendo em vista que Araújo et al (2003), em levantamento realizado com professores perceberam que estes apresentaram bom conhecimento relativo a algumas drogas como álcool, tabaco, maconha e cocaína, o que não se observa com relação a outras como solventes, anfetaminas e opióides, e demonstraram desconsiderar o contexto social do uso dessas drogas, consideramos que a formação docente também seja contemplada com informações a respeito da natureza e das ações destas substâncias no organismo.

Notamos que com relação aos tipos de danos causados pelas drogas, certa diversidade de concepções no grupo considerado, apontando diferentes aspectos, sendo que o mais aludido foi o que diz respeito aos danos e alterações psicológicas. Referências às alterações e danos físicos e sociais relacionados às drogas são bastante presentes em 
nossa sociedade, inclusive explorados fortemente pela mídia, sendo esperado que fossem aludidos pelos sujeitos da pesquisa. Ressalte-se que três asserções referiam-se a alterações e danos morais e espirituais provocadas pelas drogas.

\section{6 - CONSIDERAÇÕES FINAIS}

Ao se referirem às drogas, os docentes pesquisados, utilizaram expressões enfáticas e alarmistas, demonstrando entender estas substâncias como algo extremamente maléfico, que produz danos psicológicos, físicos, sociais, espirituais e morais, muitas vezes irreversíveis. Deduzimos que ao aludirem às drogas, estes se referem a situações extremas, mais relacionadas à dependência que às outras formas de consumo.

Supomos que tais representações estejam influindo em suas práticas pedagógicas, no que concerne ao assunto em questão. Seria interessante a realização de pesquisas que procurassem verificar esta relação.

Consideramos a metodologia adequada para os objetivos do trabalho que foi levantar alguns aspectos das representações docentes sobre drogas, mas ressaltamos as limitações do instrumento de coleta de dados utilizado no que se refere a obtenção de dados mais abrangentes sobre o assunto.

Concluímos que tais representações devem ser levadas em conta no processo de formação inicial e continuada docente, que deve buscar amplia-las. 


\section{REFERÊNCIAS BIBLIOGRAFICAS}

ANADÓN, M.; MACHADO, P. B. Reflexões teórico-metodológicas sobre as representações sociais. Salvador: Editora UNEB, 2003

ARATANGY, L. R. Drogas: uma questão de liberdade. In. SÃO PAULO (ESTADO) Papel da educação na ação preventiva ao abuso de drogas e à DST/AIDS. São Paulo: FDE. Diretoria de Projetos Especiais/Diretoria Técnica, 1996. (Série Idéias; n.29)p.109-118.

ARAUjO, C. C., FERREIRA, F. N. E., QUEIROZ, R. S., PORTO, G. G., SILVA, T. F., CAVALCANTE, C. V. G., CHAPANI.D.T.Conhecimento de um grupo de professores de ensino fundamental e médio sobre drogas psicotrópicas In: Encontro Nacional de Pesquisadores em Educação em Ciências (IV) Atas... ABRAPEC: Bauru, 2003

BRASIL, Secretaria da Educação Fundamental. Parâmetros curriculares nacionais: meio ambiente e saúde. Brasília: MEC/SEF, 1997.

Secretaria da Educação Fundamental. Parâmetros curriculares nacionais: terceiros e quarto ciclos: temas transversais. Brasília: MEC/SEF, 1998.

Secretaria Nacional Antidrogas. Política Nacional Antidrogas. Brasília: Presidência da República, Gabinete de Segurança Institucional, Secretaria Nacional Antidrogas, 2001.

BUCHER, R. Drogas e drogadição no Brasil. Porto Alegre: Artes Médicas, 1992.

Drogas: o que é preciso saber para prevenir. $3^{\mathrm{a}}$ ed. São Paulo: Fundo Social de Solidariedade do Estado de São Paulo, 1993.

BUCHER, R.,OLIVEIRA, S.R.M. O discurso do combate às drogas e suas ideologias. Rev. Saúde Pública, 28 (2), 137-145.

CARLINI-CONTRIM, B., ROSEMBERG, F. Os livros didáticos e o ensino para a saúde: o caso das drogas psicotrópicas. Rev. Saúde Pública, São Paulo 25 (4): 299-305, 1991. 
DELGADO, E., PABLOS, M.L., SÁNCHES, D.S. Programa de orientação educacional sobre prevenção à dependência de drogas. In: ÁLVAREZ, M.N. Valores e temas transversais no currículo. Porto Alegre: ARTMED, 2002

DOMANICO, A, BRITES, C.M. realidade escolar e uso de drogas. In. SÃO PAULO (ESTADO) Papel da educação na ação preventiva ao abuso de drogas e à DST/AIDS. São Paulo: FDE. Diretoria de Projetos Especiais/Diretoria Técnica, 1996. (Série Idéias; n.29) $(133-136)$.

FERREIRA, A.B.H. Novo Aurélio século XXI: dicionário de língua portuguesa. $3^{\mathrm{a}}$ ed. Rio de Janeiro: Nova Fronteira, 1999.

GALDURÓZ, J.C.F.; NOTO, A.R.;CARLINI, E.A. IV Levantamento sobre o uso de drogas entre estudantes de $1^{\circ}$ e $2^{\circ}$ grau em 10 capitais brasileiras. São Paulo: UNIFESP, 1997. Disponível em www.cebrid.epm.br. Acesso em 03/12/2004.

GOMES, R. A análise de dados em pesquisa qualitativa. In: MINAYO, M.C. S. (org) Pesquisa Social: teoria, método e criatividade. $12^{\text {a }}$ ed. Petrópolis (RJ): Vozes, 1994.

LEOPARDI, M.T. Metodologia da pesquisa na saúde. Santa Maria: Pallotti, 2001

LIMA, E.S. Drogas nas escolas:quem consome o quê? In. SÃO PAULO (ESTADO) Papel da educação na ação preventiva ao abuso de drogas e à DST/AIDS. São Paulo: FDE. Diretoria de Projetos Especiais/Diretoria Técnica, 1996. (Série Idéias; n.29) p. 119 -130

MARQUES, A.C.P.R. Atualização de Conhecimentos sobre redução da demanda de drogas (curso a distância). s.I. SENAD/UFSC, s.d.

REIGOTA, M. Meio ambiente e representação social. São Paulo: Cortez, 1995 (Questões da nossa época, v.41).

RIBEIRO, T.W.; PERRGHER,N.K., TOROSSIAN,S.D. Drogas e adolescência: uma análise da ideologia presente na mídia escrita destinada ao grande público. Psicol. Reflex.Crit.v. 11.n.3.Porto Alegre, 1998

SOARES, C.B., JACOBI, P.R. Adolescentes, drogas e AIDS: avaliação de um programa de prevenção escolar. Caderno de Pesquisa, n. 109, p.213-237, março, 2000 
SPINK, M.J. Desvendando as teorias implícitas: uma metodologia de análise das representações sociais. In: GUARESCHI, P.A., JOVCHELOVICHT (ORG) Textos em representações sociais. $2^{\mathrm{a}}$ ed. Petrópolis (RJ): Vozes, 1995 ( 117- 148).

WAGNER,W. Descrição, explicação e método na pesquisa das representações sociais. In: GUARESCHI, P.A., JOVCHELOVICHT (ORG) Textos em representações sociais. $2^{a}$ ed. Petrópolis (RJ): Vozes, 1995 ( $149-186)$. 